\title{
O uso politico do passado bandeirante: o debate entre Oliveira Vianna e Alfredo Ellis Jr. (1920-1926)
}

\author{
The political use of "bandeirante" past: the debate \\ between Oliveira Vianna and Alfredo Ellis Jr. \\ (1920-1926)
}

Danilo J. Zioni Ferretti

Por seu poder de legitimar ou deslegitimar regimes, grupos e instituições, de definir narrativas de origem, de sustentar discursos apologéticos ou mesmo de apagar eventos traumáticos, o discurso histórico mostrou-se em todos os tempos suscetível de uso político, seja ele definido pela intenção do autor ou pela recepção do destinatário (Hartog \& Revel, 2001; Quatrocchi-Woisson, 1992).

Danilo J. Zioni Ferretti é doutor em história social e professor do Curso de História da Universidade Federal de São João Del Rei - UFSJ, MG(danilozf@ufsj.edu.br).

Texto recebido em 28 de dezembro de 2007 e aprovado para publicação em 28 de fevereiro de 2008.

Nota do autor: O presente texto é fruto de pesquisa que contou com bolsas de estudo financiadas pela Fapesp e pela Capes.

Estudos Históricos, Rio de Janeiro, vol. 21, nº 41, janeiro-junho de 2008, p. 59-78. 
Neste texto, pretendo me concentrar no estudo do uso político, feito durante a década de 1920, da figura histórica do bandeirante. O tema da construção e sentido do símbolo bandeirante não é novo, tendo sido alvo do interesse de vários historiadores nos últimos 20 anos. ${ }^{1}$ Com esse campo já consolidado, pretendo adotar um enfoque que privilegie os sentidos políticos conferidos ao bandeirante mediante o estudo de sua relação com o duplo processo de construção de uma identidade regional para São Paulo e de um imaginário político americanista, legitimador do republicanismo paulista. ${ }^{2}$ Para tanto, irei me concentrar principalmente no estudo do debate político-historiográfico travado no ocaso da Primeira República entre o pensador Oliveira Vianna e Alfredo Ellis Jr., expoente de uma intelectualidade ligada ao Partido Republicano Paulista (PRP). Embora o debate se restrinja à década de 1920, procurarei, antes, definir o que considero ser o caráter liberal da identidade paulista e sua relação com a figura histórica do bandeirante, remetendo-me aos anos da propaganda republicana.

Para compreender o uso político do passado, procuro seguir a reflexão de Michel de Certeau sobre a "operação historiográfica", uma vez que ela possibilita adotar um enfoque amplo que, sem desconhecer a dimensão epistemológica e narrativa da escrita da história, ainda considera a importância do universo extratextual, do lugar social no qual o historiador está inserido e a partir do qual representa o passado (Dosse, 2004:200). Desse modo, pretendo compreender a historiografia produzida sobre o bandeirante como resultado da "relação entre um lugar (um recrutamento, um meio, uma profissão etc.), procedimentos de análise (uma disciplina) e a construção de um texto (uma literatura)" (De Certeau, 2000: 66).

\section{Republicanismo e identidade regional: o paulista como o "ianque sul-americano"}

Formado majoritariamente por produtores de café descontentes com o sistema fiscal do centralismo monárquico, o republicanismo paulista despontou na década de 1870 baseando-se em um ideário liberal que, em algumas figuras do movimento, se misturava com elementos do cientificismo positivista, principalmente na versão spenceriana (Casalecchi, 1987; Bresciani, 1993). Na esteira do federalismo de Tavares Bastos, ${ }^{3}$ os republicanos paulistas, a seu modo, tomaram também os Estados Unidos como país modelo, elaborando um projeto nacional modernizador claramente americanista.

O núcleo do projeto americanista dos republicanos paulistas estava na defesa de "reformas políticas liberais mais capitalismo agrário moderno", aspectos centrais do americanismo brasileiro de finais do século XIX, conforme a aná- 
lise de Luiz Werneck Viana (1993: 372). Ou seja, no caso dos republicanos paulistas, a liberalização do mundo da política seria marcada pela defesa de uma república federativa que respeitasse a autonomia das províncias e se baseasse em uma nova legitimidade, identificada exclusivamente no princípio liberal da "representação popular", uma autoproclamada "democracia" que, no entanto, procurou se resguardar da participação das massas. Ao mesmo tempo, o programa de afirmação do "capitalismo agrário moderno" seria marcado pela ocupação do sertão mediante a expansão da fronteira cafeeira, a implementação de uma ampla rede de estradas de ferro e uma forte política populacional imigrantista. Assim, definia-se um novo horizonte de expectativa da elite republicana paulista, marcado pelo anseio de transformar a província de São Paulo em uma verdadeira utopia liberal, caracterizada por autonomia política e progresso material, à imagem e semelhança do que se entendia serem os Estados Unidos.

Essa versão paulista de projeto americanista, liberal, excludente e autoritária, ${ }^{4}$ juntamente com a autoconfiança desses arrivistas do café, marcou fortemente o novo discurso de identidade regional que eles se dedicaram então a construir. O sentido do discurso podia ser novo, mas o empenho na construção de uma identidade paulista, em "fazer ver" São Paulo e o seu habitante, remontava pelo menos ao século XVIII com as obras dos cronistas Frei Gaspar e Pedro Taques. Mas a partir da década de 1870 redefiniam-se os termos da relação entre o nacional e o regional, não somente no universo político, como também no cultural-identitário. Visando a legitimar a demanda federalista do republicanismo, tendia-se a frisar a diferença de um pretenso caráter paulista diante do todo nacional. A identidade regional passava a adquirir maior autonomia, chegando mesmo a se opor à nacional durante o minoritário e breve movimento separatista de 1887 (Aducci, 2000).

Por esse novo discurso identitário dos republicanos, o "povo paulista" seria, antes de tudo, uma avis rara, uma "exceção de progresso" em meio aos demais brasileiros (com destaque para os "nortistas"), vistos como apáticos e dependentes do governo. Mais do que isso, ele seria dotado das mesmas qualidades que então identificavam no povo norte-americano, o representante da humanidade redimida do despotismo. O mesmo "espírito de iniciativa", a mesma "liberdade", o mesmo "espírito empreendedor", a mesma aversão a um poder estatal repressor uniriam ianques e paulistas. Se, desde a década de 1870, várias menções ao caráter "americano" dos paulistas já apareciam, ${ }^{5}$ a definição lapidar veio em 1913, do historiador das bandeiras e republicano mineiro Basílio de Magalhães. Referindo-se aos paulistas, considerava ele que "o segredo de sua força, o segredo de seu progresso está na portentosa iniciativa de seus filhos, que podem, com razão, ser chamados os ianques da América do Sul" (Magalhães, 1913: 30, 31). 
O termo "ianque da América do Sul" era uma pequena variação do "ianque hispano-americano" que o expoente dos americanistas argentinos, Juan Bautista Alberdi, concebia como um verdadeiro projeto de Homem Novo, dotado de uma ética adequada aos valores do modelo americano que procurava aplicar (Viana,1993: 357-360). Exemplo maior desse caráter ianque auto-atribuído pelos paulistas está naquele que se transformou em um dos principais símbolos regionais: a bandeira do estado de São Paulo. A "bandeira das treze listras" foi concebida nesse mesmo contexto, em 1888, como uma imitação, em outras cores, da bandeira norte-americana, pelo romancista republicano (e separatista) Júlio Ribeiro.

A idéia de que, ao contrário dos demais brasileiros, o paulista era dotado de uma índole livre e independente diante de governos arbitrários encontrou no discurso historiográfico o seu principal suporte. A afirmação da originalidade regional estava conectada a uma interpretação mais ampla do passado nacional. Especificamente, ela partia de uma prévia interpretação liberal do passado brasileiro, consolidada, entre outros, por Tavares Bastos, que o entendia como um processo de contínuo embate entre os princípios da liberdade e da autoridade. Essa interpretação liberal do nosso passado implicava elaborar um diagnóstico que identificava os males nacionais como fruto de uma espécie de onipresença estatal, que lançava raízes no que entendiam como "absolutismo colonial" de matriz ibérica, espécie de versão nacional e atenuada do despotismo asiático (Rego, 1993: 167-168). E o mais interessante era que, mesmo nessa reinterpretação do passado, eles não perdiam de vista o exemplo norte-americano, que, como contraponto positivo, ressaltava a negatividade da formação brasileira. Para o republicano paulista Alberto Salles, aqui seguindo explicitamente Tocqueville, "é justamente em sua origem [do povo americano] que se descobre o segredo de sua prosperidade" (Salles, 1879: 155, 156). Mais adiante, afirmava que "a nação americana visa a liberdade desde o berço, enquanto pesavam em nossos pulsos as algemas do absolutismo português. (...) E as causas do nosso atraso geral devem ser procuradas no absurdo sistema de colonização adotado por Portugal" (Salles, 1879: 169).

Mas, se o diagnóstico da (má) formação brasileira apontava para uma origem espúria, o sucesso excepcional reputado ao paulista implicava afirmar um passado diferente para São Paulo. Para tanto, a elite regional apropriou-se de trechos do historiador português Oliveira Martins, visando a demonstrar a fragmentação da trajetória histórica brasileira no período colonial. Afinal, para aquele autor, entre o fim do século XVII e o início do XVIII, o Sul, do qual São Paulo seria o cerne, e o Norte "apresentam-se-nos, na América portuguesa, como duas grandes províncias, cuja história é diversa, porque os seus caracteres naturais e adquiridos foram diferentes até a unificação selada com a independência" 
(Martins, 1978 [1880]: 75). Esse trecho, que consagrava uma história específica para São Paulo, seria citado por Alberto Salles e serviria de epígrafe para as obras de Washington Luís, Paulo Prado, Alfredo Ellis Jr. e Afonso de Taunay, evidenciando sua centralidade para a historiografia regional até meados do século XX.

Pela afirmação de um passado comum aos paulistas - e diferente dos demais brasileiros - a elite regional redefinia o seu campo de experiência e explicava a exceção que pretendia representar. Identificou-se então a existência, na São Paulo colonial, de uma "época de ouro". Correspondendo grosso modo ao século XVII, ela implicava um original regime de semi-independência em relação à autoridade da coroa portuguesa, baseado em vigorosa atuação das câmaras municipais, como se o "absolutismo colonial", presente nas plagas do Norte, estivesse ausente da primeira formação paulista.

O vínculo entre esse discurso histórico da "liberdade primitiva do paulista" e o republicanismo provincial mostrou-se de forma explícita na obra do deputado republicano Américo Brasiliense. Em 1878, ele escreveu o livro O Programa dos partidos no Segundo Império, onde historiava as agremiações políticas então existentes. Ao tratar do caso do Partido Republicano Paulista (PRP), ao contrário do que fez com todos os demais partidos, lançou sua origem para o remoto passado colonial. E a explicação que apresentou para as origens do PRP era a mesma que apontava para o caráter paulista: um período colonial livre e independente do absolutismo metropolitano, no limite democrático. Assim, Brasiliense afirmava que o PRP era fruto do "entusiasmo pelos princípios liberais", da "altivez e independência do espírito paulista", de uma "notável expansão da vida municipal" na época colonial, quando as câmaras "não procediam só por sua deliberação", mas "convidavam o povo para uma ou às vezes mais reuniões" (Brasiliense, 1878: 96, 97). Brasiliense não somente identificava uma versão paulista da township, do governo comunal - tão louvado por Tocqueville como célula mater da democracia norte-americana -, como também consolidava um mito de origem perrepista que, não por acaso, correspondia ao cerne do novo discurso identitário regional, baseado no princípio da liberdade primitiva do paulista.

Ao mesmo tempo, iniciava-se um movimento de reavaliação positiva da figura do bandeirante que, desde os anos 1830, vinha sendo desqualificado pela intelectualidade indianista da Corte, sendo apresentado como um famigerado caçador de índios, síntese dos piores vícios do colonizador. Nos anos 1870, autores como Azevedo Marques (1954 [1879]: 17) e o republicano Américo Brasiliense (1875:115) buscavam timidamente absolvê-lo da pecha de assassino egoísta de que havia sido acusado. Mas, se os republicanos somente começavam a investir na figura do bandeirante, o trabalho completo nesse sentido seria realizado após a proclamação da República, quando esses mesmos republicanos criaram, junto com outros grupos, o Instituto Histórico e Geográfico de São Paulo (IHGSP) em 1894, exatamente o ano em que o primeiro presidente paulista subiu ao poder. 
Fruto de uma verdadeira política cultural do novo governo sob o comando do secretário do interior Cesário Mota, o IHGSP transformou o que era contra-história em história oficial, institucionalizando a produção da visão republicana do passado colonial paulista. A partir de então, toda uma vertente liberal-republicana, interna ao IHGSP, empenhou-se em enraizar as novas instituições republicanas no terreno estável das tradições.

Na primeira década do século XX, expoentes dessa corrente, Antônio de Toledo Piza e Washington Luís Pereira de Sousa, então jovem advogado recém-chegado a São Paulo, procuraram integrar a figura do bandeirante nesse panteão republicano. O bandeirante dos artigos de Washington Luís, mais do que herói construtor do território, destacava-se por possuir um espírito livre e até democrático, representado tanto na insubmissão ao poder da coroa portuguesa quanto na participação ativa nas câmaras municipais que, em São Paulo, "jamais fora[m] tão forte[s] e vigorosa[s] como no século XVII” (Sousa, 1918: 60). Mais especificamente, Washington Luís procurava apresentar, em seu principal estudo, o momento de supressão dessa liberdade paulista, identificado com o governo de $\mathrm{D}$. Rodrigo César de Meneses na década de 1720, não deixando, porém, de sugerir a futura recuperação dessa mesma liberdade pelo federalismo republicano.

O destaque como o principal construtor da legitimação simbólica do novo regime ajudou o fluminense Washington Luís a consolidar laços sociais com a elite paulista e a trocar a historiografia pela política. Uma vez no poder, como prefeito da capital paulista ou como presidente do estado, de 1916 a 1924, articulou a difusão maciça desse imaginário bandeirante, de forte caráter liberal, aproveitando o ensejo das comemorações do Centenário da Independência. Pôs em prática, então, uma verdadeira política de identidade, mobilizando recursos para incentivar o que então se chamou de "culto ao passado paulista".

Inicialmente, Washington Luís financiou a publicação de um dos maiores corpus documentais de história regional - as "Atas da Câmara da Vila de São Paulo" e a série de "Inventários e Testamentos" -, que foi a condição para o boom de publicações sobre a história paulista nos anos 1920, representado pelas obras de Alfredo Ellis Jr., Alcântara Machado, Paulo Prado e Afonso de Taunay. Washington Luís ainda patrocinou a transformação do Museu Paulista, no Ipiranga, em uma verdadeira catedral bandeirante, construiu os Monumentos da Serra do Mar, elevou, em Porto Feliz, uma coluna rostral em homenagem às monções e, em 1923, criou o Museu Republicano Convenção de Itu, em que apresentava, como ponto máximo da história paulista e brasileira, nada menos do que o evento fundador do republicanismo paulista.

Todo esse investimento simbólico revestiu-se de uma ampliada significação política no contexto dos anos 1920, quando se intensificaram as críticas ao 
status quo e se iniciou a crise da República liberal-federalista defendida pelo grupo perrepista. Entre os grupos críticos que então surgiam, em sua vertente especificamente antiliberal e centralizadora, destacou-se Oliveira Vianna, que, na elaboração de seus ataques às instituições políticas vigentes, também lançou mão do passado bandeirante, porém ressignificando-o.

\section{Oliveira Vianna e a crítica historiográfica à República liberal-federalista}

Apesar de conferir destaque à temática bandeirante e paulista no conjunto de sua obra, Francisco José de Oliveira Vianna não pertencia ao meio social e político de São Paulo. Na realidade, manteve uma relação paradoxal com a elite paulista da Primeira República, que procuraremos aqui compreender: ao mesmo tempo que conquistava entusiásticos elogios e adesões, também gerava obstinadas recusas.

O início dessa tumultuada relação foi marcado pela proximidade e pelo entusiasmo recíprocos. Fluminense de Saquarema, Oliveira Vianna iniciou sua atividade intelectual no Rio de Janeiro da década de 1910, escrevendo artigos para o jornal O Paiz que logo chamaram a atenção do pensador Alberto Torres. Este incorporou o jovem estudioso no círculo de intelectuais reunidos ao seu redor. Entre discussões sobre questões de sociologia, direito e organização nacional, o grupo dedicava-se, então, a fazer a crítica da Constituição republicana de 1891, principalmente em seu aspecto federalista, o que marcou fortemente a produção de Oliveira Vianna (Torres, 1956). Mas, se o lugar social a partir do qual o autor pensou o passado nacional foi o do grupo nacionalista fluminense na sua vertente antiliberal, sua projeção nacional se deu por intermédio da intelectualidade paulista (Venâncio, 2003: 188-220). De fato, Oliveira Vianna manteve-se como um semi-obscuro professor de direito de Niterói até ver seus artigos serem publicados, a partir de 1917, na Revista do Brasil. Tratava-se do prestigioso órgão de difusão dos valores da nova vaga nacionalista, concebido em 1916 pelo grupo do jornal O Estado de S. Paulo (OESP), um dos bastiões do liberalismo paulista e, desde 1918, pertencente a Monteiro Lobato (Luca: 1999). O forte incentivo de Lobato a Oliveira Vianna revela um dos momentos de interesse da intelectualidade paulista por sua obra, explicável, entre outros elementos, pelo tom nacionalista comum e pela centralidade que o autor fluminense conferia ao papel de São Paulo nas suas análises do passado.

Mas, se setores da intelectualidade liberal paulista ajudaram a projetar Oliveira Vianna, o resultado de sua produção intelectual voltar-se-ia, ironicamente, contra as próprias instituições e valores políticos que essa mesma intelectualidade defendia. Pois, nos termos do pensamento de Oliveira Vianna, aquilo 
que constituía a sua verdadeira cruzada era a luta contra o "Idealismo Utópico" de nossas elites dirigentes, "quimeras" ideológicas diretamente identificadas com os princípios políticos do liberalismo. Como uma legião de autores já indicou, Oliveira Vianna baseava sua desqualificação do liberalismo no argumento da "planta exótica", de sua inadequação à realidade específica brasileira (Viana, 1993: 381).

O autor considerava que o liberalismo e a democracia não eram valores absolutos e universais, mas formas de governo que exigiam dos seus agentes uma "psicologia política" específica, não encontrada em todos os povos: "na verdade só [a] encontramos (...) em certos grupos privilegiados: no saxão insular; no seu ramo americano; nos povos germânicos em geral; entre os antigos romanos; no grupo nipônico" (Oliveira Vianna, 1930 [1921]: 49). Com essa acusação de inadequação das "exóticas" instituições liberais à realidade brasileira, Oliveira Vianna dedicava-se a tecer a mais acerba crítica ao americanismo republicano, pejorativamente qualificado como "coqueluche anglo-saxônica". Afinal, considerava que "o que devemos querer não são regimes belos ou harmônicos, mas sim regimes convenientes e adaptados ao nosso povo" (Oliveira Vianna, 1981 [1930]: 118). E, seguramente, o que indicava esse desacordo profundo entre o "nosso povo" e as instituições liberal-federalistas "importadas" do modelo anglo-saxão era uma análise pormenorizada de nossa formação histórica.

Portanto, para dar corpo à sua crítica de natureza claramente política, 0 autor, como de costume à época, lançou mão do estudo do passado. A seu ver, os "estudos históricos" tinham um "caráter pragmático", servindo como guia na elaboração de um novo direcionamento político para o Estado. Oliveira Vianna adaptava o velho bordão ciceroniano a suas demandas imediatas e concluía ser a história mais que a mestra da vida, a "mãe e mestra da política" (Oliveira Vianna, [1923] 1956: 38). Essa explícita função política da história não era entendida como algo que minorasse o seu caráter científico. Muito pelo contrário, era a cientificidade do saber histórico-social que garantia a sua validade como guia da ação política. Daí o investimento de Oliveira Vianna em discussões de natureza metodológica, que indicavam algumas transformações na forma como então se concebia a escrita da história nacional, conforme explicita em seu discurso de ingresso no IHGB.

Primeiramente, ele rompia com o paradigma metódico ao criticar o que chamava de "fetiche do documento", lembrando que não bastava a realização da crítica documental e o conseqüente encadeamento das fontes para trazer à vida a imagem do passado. A partir desse ponto, demonstrava um traço de atualização, nem sempre lembrado pelas análises, ao se aproximar de ninguém menos que Henry Berr, um dos gurus do grupo dos Annales, que se constituía por aqueles anos. Citando Berr (1924), Oliveira Vianna defendia que a reconstituição do pas- 
sado dar-se-ia pela realização da "síntese histórica", marcada pela utilização, de forma federativa, do saber das demais disciplinas das ciências sociais. Mas, diversamente do que fizeram os historiadores dos Annales, o autor privilegiou as velhas correntes da sociologia oitocentista, próximas ao racismo científico e ao organicismo evolucionista, para auxiliar na exegese documental. Com essa base teórica, elaborou a sua principal obra, Populações meridionais do Brasil, publicada em 1920.

Nesse livro, o autor procurava definir o que considerava ser a "realidade" do Brasil, de forma que a obra pode ser considerada a verdadeira chave de seu pensamento e a base de toda a sua crítica ao liberalismo da Primeira República. Oliveira Vianna conferia papel central ao latifúndio rural como base da formação social "insolidária" brasileira. Dele se originara uma aristocracia de caudilhos rurais que, a expensas de uma autoridade estatal metropolitana, vista como fraca e impotente, impunham seu poder arbitrário sobre toda a vida colonial, impedindo a constituição de um mínimo de "solidariedade social". Conforme a análise de José Murilo de Carvalho, o diagnóstico da nação apresentado pela historiografia de Oliveira Vianna invertia o sentido consagrado pela matriz liberal, presente em Tavares Bastos e em republicanos paulistas como Alberto Salles (Carvalho, 1993: 20). Enquanto essa matriz afirmava que o entrave ao progresso da nação estava na onipotência do poder estatal, entendido nos termos do "absolutismo colonial", para Oliveira Vianna o despotismo não viria "de cima", do Estado colonial absolutista português, mas sim "de baixo", da preponderância do poder privado dos próprios colonos. Para o pensador fluminense, se havia algum despotismo colonial, seus agentes seriam os turbulentos caudilhos rurais, que se confundiam com os bandeirantes, entendidos como antepassados políticos do mandão rural de sua época.

Na contramão da visão consagrada pela matriz liberal, compartilhada pelos historiadores paulistas, Oliveira Vianna apresentava outra representação da formação nacional, que aqui retratamos somente em seus traços principais. ${ }^{6}$ Por ela, o período colonial seria marcado essencialmente pela "insolidariedade", fruto da atuação preponderante da extensão do meio americano e do latifúndio semi-autônomo. A instância preponderante era a dos interesses privados dos caudilhos rurais, que provocavam a ausência da autoridade política universal, fazendo prevalecer a "anarquia colonial". Sob essa ótica, as instituições liberal-federalistas republicanas, no seu esforço descentralizador, somente viriam reforçar o dado problemático de nossa formação, aprofundando ainda mais o despotismo privado. Afinal, para o autor, "entre nós, liberalismo significa praticamente, e de fato, nada mais do que caudilhismo local" (Oliveira Vianna,1920: 257), o que impediria a realização da "síntese orgânica" que entendia ser a condição para a consolidação da nacionalidade. No diagnóstico da formação nacional que esta- 
belecia em sua historiografia, Oliveira Vianna procurava legitimar sua defesa da instituição de um Estado forte e centralizado - instrumento do "idealismo orgânico" que preconizava -, que deveria substituir as instituições liberais federativas da Primeira República defendidas acirradamente pelos republicanos paulistas. Oliveira Vianna se distanciava, nesse ponto, da elite paulista.

Por outro lado, não deixou de compartilhar com ela seu entusiasmo pela figura do bandeirante, alçado ao papel de protagonista de nossa história colonial. Mas o seu bandeirante não era exatamente o mesmo de Washington Luís, ou dos demais colegas do IHGSP, e em torno dos valores atrelados à sua figura se desenvolveu uma acirrada luta de representações. Do lado de Oliveira Vianna, a representação que produziu do bandeirante destacou-se por três características principais. Em termos sociais, ele foi visto como um aristocrata; em termos políticos, era um caudilho turbulento e anarquizante; e em termos raciais, um ariano. Mais do que a conquista do território, o papel central da bandeira, para o pensador fluminense, estaria na expansão do latifúndio por amplas superfícies até então despovoadas. Fruto do latifúndio, o bandeirante seria seu maior propagador, sendo a própria bandeira interpretada como uma espécie de "latifúndio em marcha" (Oliveira Vianna, 1920: 78,79), imagem posteriormente incorporada por Cassiano Ricardo no seu épico Marcha para Oeste (1940). O bandeirante, entendido como o grande proprietário de terras, assumia, assim, um caráter socialmente aristocrático, e a bandeira era descrita pelos valores da ordem e hierarquia. Oliveira Vianna elogiava o caráter "prussiano" de sua organização, em que o aristocrata bandeirante mantinha uma rígida ordem interna, submetendo mulatos e mamelucos. Ao mesmo tempo, essa organização hierarquizada afastava os grupos subalternos de comerciantes, mestiços e negros do mundo da política, concentrando nas mãos do grupo latifundiário o direito de participação nas câmaras, sustentado, a seu ver, "por salutares preconceitos" (Oliveira Vianna, 1920: 100). Da mesma forma como havia negado a existência do absolutismo colonial, o autor mais uma vez solapava a interpretação liberal de nossa história ao identificar a degeneração do princípio do self-government, representado pelas câmaras coloniais, quando em contato com o latifúndio dos sertões brasileiros. Ao considerar as câmaras como "centros de caudilhismo eleitoral", em que inexistia a participação independente dos indivíduos do povo (Oliveira Vianna, 1920: 150-151), impossibilitava a miragem da existência de uma protodemocracia social e política na São Paulo seiscentista, esboçada pelos republicanos paulistas. Ao mesmo tempo, frisava a diferença da formação brasileira em relação à dos países de tradição liberal-democrática, pois faltava-nos a township americana, ou a dos burgos europeus, entendidos como berços de virtudes cívicas (Viana, 1993: 375).

Se, socialmente, o bandeirante servira, na visão de Oliveira Vianna, para a benéfica função de manter a ordem "prussiana" interna ao latifúndio, em termos políticos mais amplos sua herança não era vista como das mais positivas, 
uma vez que era identificado como um dos grandes agentes incentivadores da turbulência e insolidariedade que marcaram nossa formação. Sendo considerado um "caudilho rural", o bandeirante paulista fora responsável pelo estado de profunda instabilidade e anarquia política que marcou o período colonial brasileiro. Mais uma vez, o autor invertia o sentido atrelado ao herói regional pelos republicanos paulistas. O que eles identificavam no bandeirante como "liberdade primitiva” era ressignificado por Oliveira Vianna como sendo a mais prejudicial "anarquia política".

Já no terreno racial, o autor foi o expoente brasileiro da teoria ariana, propagada desde o século XIX pelas obras do conde de Gobineau e de seus seguidores Lapouge e Quatrefages, que defendia a superioridade do tipo germânico puro (Poliakov, 1974). Sob esse enfoque, Oliveira Vianna sugeria ser o bandeirante um germânico, herdeiro da aristocracia portuguesa composta por cruzados borguinhões e normandos da época da formação do reino. Longe de qualquer sombra de democratismo racial, ele seria um "dolicóide louro" de elevada estatura, cioso de sua pureza e dotado de todos os atributos físicos e psicológicos positivos que isso pretensamente implicava, tais como "sua combatividade, seu nomadismo, essa mobilidade incoercível” (Oliveira Vianna, 1923: 131). O bandeirante (e, por conseguinte, a moderna elite paulista) era considerado o mais fiel representante do tipo ariano germânico no Brasil.

Essa posição tinha claros desdobramentos na forma como concebia a posição e o papel da elite paulista sua contemporânea. Em uma série de artigos publicados de agosto de 1926 a janeiro de 1927 no Correio Paulistano, o órgão oficial do PRP, Oliveira Vianna atestava o caráter eugênico da elite cafeicultora paulista, contribuindo, dessa forma, para o movimento de autolegitimação dessa mesma elite regional. Tratava-se de mais um momento de convergência entre o pensador fluminense e a elite paulista, que ampliava ainda mais o caráter paradoxal de seu relacionamento.

O tom geral dos artigos tendia a apresentar São Paulo como fadado desde suas origens à superioridade, em função da permanência por quatro séculos do caráter eugênico de sua elite. No contexto dos anos 1920, em que o poder dessa mesma elite paulista vinha sendo contestado, Oliveira Vianna reafirmou sua vocação quatro vezes secular na condução dos destinos nacionais, restringindo-se ao aspecto específico do elogio às suas características raciais e aristocráticas. Mas, como vimos, nem tudo era elogio no que dizia respeito à elite de São Paulo.

$\mathrm{O}$ autor apresentava uma visão própria da identidade paulista, negando a identificação com o "ianque" em seu aspecto político. Pois o paulista, a seu ver, não era dotado de um espírito "livre" e "democrático", semelhante ao do americano do Norte, conforme afirmava o imaginário perrepista. Referindo-se à sua "psicologia política", o paulista moderno, com seu liberalismo, era entendido 
como herdeiro do "caudilhismo anárquico" do século XVII, e não da antiga "democracia" piratiningana. A identidade do paulista, para Oliveira Vianna, somente se comparava à do ianque pelo fato de ambos possuírem o que chamava de "idealismo pragmático", um terceiro "idealismo" (ao lado dos idealismos utópico e orgânico) que não era precisamente definido pelo autor, mas que se aproximava dos valores da eficiência e da praticidade, que implicava "intuição econômica" e "ambição de vôo largo" (Oliveira Vianna, 1930: cap. V). Mas esse "idealismo pragmático" do paulista moderno ainda não era o "idealismo orgânico" antiliberal, estatista e centralizador que o autor considerava imprescindível à formação da futura elite dirigente.

Dessa maneira, Oliveira Vianna mantinha uma relação ao mesmo tempo de aproximação e distanciamento, tanto da identidade paulista elaborada pela elite regional, quanto do próprio papel político desempenhado por essa elite na Primeira República. Apresentava-se, ao mesmo tempo, como crítico e entusiasta da elite política paulista. Crítico quanto aos aspectos da psicologia política do paulista, que condenava como liberal, e portanto, anarquizante. E entusiasta quanto aos aspectos sociais e raciais, que louvava como exemplares pelo seu aristocratismo e arianismo. Sua admiração pela "eugenia ariana" e o caráter "aristocrático" do paulista, tanto o antigo quanto o moderno, era diretamente proporcional à condenação que fazia do papel liberal "anárquico" que desempenhava em termos políticos, tanto no passado bandeirante quanto no presente republicano.

Suas idéias foram recebidas de formas diversas no seio da intelectualidade perrepista. Mas a tendência geral foi suscitar críticas dos historiadores que, naquela década, publicaram várias obras sobre o passado regional. Se Alcântara Machado e Afonso de Taunay levantaram algumas críticas, as principais ficaram a cargo do jovem Alfredo Ellis Jr.

\section{Alfredo Ellis Jr. e a busca das origens da "democracia paulista"}

Na mesma época em que Oliveira Vianna desferia seus golpes na base de legitimação da república liberal-federalista, de 1917 a 1924, formou-se um grupo de intelectuais fiéis ao PRP, que atuou conjuntamente pelo menos até o final do regime, em 1930. Congregados em torno da redação do Correio Paulistano, então órgão oficial do governo paulista, essa intelectualidade perrepista empenhava-se na defesa do status quo republicano e na difusão de um discurso laudatório da paulistanidade. Composta pela ala verde-amarela do modernismo (Menotti Del Picchia, Plínio Salgado e Cassiano Ricardo) e por figuras como os historiadores Afonso de Taunay e Alfredo Ellis Jr., além de outros, eram liderados e eventualmente financiados por Washington Luís e demais presidentes de São Paulo. 
Constituíam-se nos guardiões ideológicos do perrepismo, dedicados a legitimar os atos do governo e a levar adiante a política de culto ao passado paulista, de que já tratamos.

A obra de Oliveira Vianna teve uma recepção diferenciada por parte dessa intelectualidade perrepista. Uma vez que os ataques ao status quo republicano vinham de pelo menos duas frentes - da oposição liberal, então representada pelo Partido Democrático (PD), e dos críticos antiliberais, como Oliveira Vianna e Alberto Torres -, a intelectualidade partidária também dividiu suas frentes de atuação e, com elas, as formas de apropriação do pensamento de Oliveira Vianna. A tríade de verde-amarelos, em vários momentos, se apropriou do antiliberalismo de Oliveira Vianna, identificando-se com ele para refutar os ataques da oposição liberal, e chegando a identificar o PRP como o verdadeiro representante do "idealismo orgânico" preconizado por Vianna (São Paulo, 1927: 205). Já Ellis Jr., membro da tradicional família Cunha Bueno, filho de um dos fundadores do PRP e ele mesmo deputado estadual pelo partido de 1926 a 1930, buscou refutar a interpretação histórica de Oliveira Vianna. Inserindo-se de forma original no grupo verde-amarelo, mantinha maior fidelidade à tradição liberal-federalista do republicanismo paulista, que buscou renovar pela sua historiografia. Esforçou-se então por produzir uma história bandeirista que seria uma verdadeira busca das origens do que chamava de "democracia paulista". Para tanto, elaborou uma versão própria da imagem do bandeirante, articulando três características principais, todas marcadas pelo sinal da democracia: racialmente, o bandeirante seria um mestiço eugênico; socialmente, seria fruto de setores médios (com predominância plebéia); e, politicamente, seria autônomo, dotado de valores liberais e de self-government.

Partindo de um enfoque antropo-sociológico semelhante ao de Oliveira Vianna, em seu livro Raça de gigantes, de 1926, Ellis Jr. inicialmente concentrou seus esforços no tratamento do aspecto racial do bandeirante. Analisando o tipo português, desenvolveu um amplo, prolixo e detalhado panorama da história racial da península Ibérica, tendo como objetivo explícito contestar a tese, defendida por Oliveira Vianna, da existência de uma aristocracia racialmente germânica no Portugal quinhentista. O autor se esforçou por mostrar a diluição e o quase desaparecimento dos poucos germânicos (dólicos-louros) que se fixaram na península, apontando para uma tendência oposta de afirmação inconteste do dólico-moreno como o tipo predominante na população portuguesa, tanto em seu presente quanto no século XVI (Ellis Jr., 1926: 57). Ellis Jr. deu continuidade à corrente regional paulista de louvação do caráter mameluco do bandeirante, fruto da mestiçagem do dólico-moreno lusitano e dos índios guaianás. Na visão do autor, a mestiçagem paulista havia sido a única no Brasil a dar certo, tendo o mameluco bandeirante sido o fruto de uma "sub-raça" nova e incomparavelmente 
eugênica. Pela falta de preconceitos que pretensamente evidenciava, seu caráter mestiço reforçava, no aspecto racial, o traço democrático do tipo paulista.

Ao abordar as características sociais do colono paulista, Ellis Jr. visava a contestar Oliveira Vianna e a tese da origem aristocrática do bandeirante, procurando, ao contrário, ressaltar suas origens plebéias e burguesas. Para o autor paulista, os primeiros povoadores do planalto paulista deveriam ser buscados nos grupos medianos que se destacavam pela sua qualidade racial, sendo os depositários da eugenia peninsular: na plebe, na burguesia portuguesa e na nobreza empobrecida de Portugal. Assim, a riqueza e o luxo aristocráticos que Oliveira Vianna identificava nas origens de São Paulo eram substituídos, em Raça de gigantes, por uma pobreza espartana, valorizada positivamente por um enfoque racial que a considerava um importante fator de seleção e "endurecimento" da raça paulista. Vale considerar que também José de Alcântara Machado, outro membro do PRP que se lançou ao estudo da história paulista nos anos 1920, ressaltou, em seu livro Vida e morte do bandeirante, a pobreza dos primeiros anos paulistas, tendo em vista o duplo propósito de contestar Oliveira Vianna e afirmar a originalidade da formação paulista em relação à nordestina, esta sim encarada como opulenta e luxuosa.

Nos primórdios de São Paulo, Ellis Jr. ainda identificou um universo marcado pela mais completa igualdade social entre os colonos. Seu estabelecimento no planalto paulista foi apresentado como um verdadeiro reinício, como a fundação de uma nova sociedade marcada pelos valores de uma democracia social. Contestando diretamente a origem aristocrática do bandeirante preconizada por Oliveira Vianna, o liberal Ellis Jr. inventava uma origem socialmente democrática para a sociedade paulista, representando-a à imagem e semelhança da sociedade colonial norte-americana, conforme a descrevia o pensamento americanista do século XIX. A esse respeito Ellis Jr. era bastante explícito, amparando sua caracterização das origens de São Paulo em Laboulaye, um dos luminares do liberalismo francês filo-americano do século XIX. Em nota de rodapé, o autor paulista explicava:

O estado de nivelamento social do planalto, durante esses estágios primevos, é bem aquele que o historiador Laboulaye, no seu Histoire des États Unis, vol. 1, 138, ao descrever a colônia de New Plymouth, pinta com mão de mestre: ' '... todos irmãos pela fé e pelo sofrimento, iguais de condições e sorte, o que mais poderiam ser, senão uma pura democracia. Não havia ali um chefe guerreiro dividindo a terra entre seus companheiros de armas (...). A igualdade era absoluta entre os peregrinos'. ( Ellis Jr., 1926: 296) 
O americanismo de Ellis Jr. estava baseado no liberal francês Laboulaye e na versão cientificista do antropogeógrafo francês Edouard Demolins, autor de $A$ quoi tient la supériorité des anglo-saxons?, livro explicitamente citado. Valendo-se da apropriação desses autores, Ellis Jr. procurava conferir solidez à sua peculiar representação do período colonial paulista, levando ao limite a idéia de uma democracia primitiva piratiningana, defendida pela tradição de autores republicanos.

No entanto, o "caráter democrático" do paulista não ficaria restrito aos seus primórdios e ao terreno social. Ellis Jr. o identificaria como estando também no próprio cerne da "psicologia política" do paulista moderno. Nesse sentido, Ellis Jr. deu ênfase ao estudo da "evolução da psicologia paulista", acabando por conferir um caráter cientificista ao velho tema da liberdade primitiva do paulista, também contestado pela representação historiográfica de Oliveira Vianna.

Apesar de considerar que o paulista antigo mantinha certo respeito, de origem ibérica, à autoridade real, Ellis Jr. ressaltava que a pobreza e o afastamento geográfico impostos pelo meio planaltino levaram à organização de um governo próprio durante o século XVII e à conseqüente transformação da psicologia política do colono paulista. Nesse sentido, Ellis Jr. qualificou o governo autônomo paulista como um regime "de verdadeiro self-government, saturado de democracia” (Ellis Jr., 1926: 223). Ellis Jr. passava a afirmar o caráter liberal e democrático também das tradições políticas dos paulistas, aproximando o passado colonial paulista do modelo norte-americano de colonização, conforme descrito pelos liberais franceses do século XIX.

Mas Ellis Jr. ia além e relacionava esse espírito liberal do paulista a uma peculiar forma de organização fundiária na São Paulo colonial, o que o levava, mais uma vez, a contestar a tese de Oliveira Vianna da predominância do latifúndio (e do espírito aristocrático dele decorrente) em todo o centro-sul colonial. Para Ellis Jr., o latifúndio não predominava na São Paulo colonial, sendo o planalto caracterizado pela pequena propriedade, base material do espírito democrático vigente em Piratininga. O regime de pequena propriedade era transformado em mais uma das especificidades da história regional que auxiliavam a explicar a "exceção paulista".

Mas as conseqüências sociais da pequena propriedade vigente nos séculos XVI e XVII, aos olhos de Ellis Jr., num primeiro momento, pareciam distanciar o bandeirante do tipo norte-americano em um aspecto: enquanto este era identificado como "particularista", o paulista colonial era entendido como um tipo "semi-rural e comunitário", uma vez que a pequena propriedade aproximava os colonos ao redor das vilas do planalto. Ellis Jr. vacilava ao representar o tipo social do bandeirante, apresentando-o como um tipo intermediário entre o 
saxão e o ibérico, dotado dos "atributos de temeridade, audácia, espírito ávido de aventuras e cheio de arrojo" do primeiro e do "espírito comunitário" do segundo (Ellis Jr., 1926: 275). O paulista antigo teria todas as características do anglo-saxão, exceto o seu caráter "particularista".

Mas com as mudanças ocorridas ao longo dos séculos XVIII e XIX, principalmente com o advento do latifúndio cafeeiro, o paulista se isolava no sertão, perdendo o contato com os demais povoadores e o caráter comunitário correspondente. "Daí, o particularismo era forçoso, tinha que tomar um grande impulso, com a absoluta eliminação das bases do comunitarismo (...). E assim, o paulista se identificou definitivamente com o individualismo, atingindo o pináculo da sua evolução" (Ellis Jr., 1926: 290). Ou seja, Ellis Jr. procurou comprovar que o advento do latifúndio escravista cafeeiro no século XIX acentuou ainda mais os traços ianques do caráter regional, transformando o paulista moderno em um ianque completo, dotado de iniciativa, temeridade etc., e também do espírito particularista que lhe faltava.

\section{Conclusão}

$\mathrm{Na}$ crise de hegemonia do grupo perrepista, ocorrida nos anos 1920, o passado colonial foi mobilizado para sustentar argumentos políticos e projetos de Estado e Nação, conferindo diferentes sentidos ao símbolo bandeirante. Com sua obra, Oliveira Vianna, além de louvar a excelência étnica do paulista, solapava as bases de legitimação simbólica do grupo liberal perrepista no poder, ao apresentar a inadequação das instituições políticas liberais à nossa tradição nacional. Pela ação predominante do bandeirante, entendido como um caudilho rural turbulento, fruto da extensão territorial americana e do latifúndio, o Brasil teria uma formação diferente da dos povos saxões aptos à forma democrático-liberal, segundo Oliveira Vianna.

Por outro lado, em seu conjunto, Raça de gigantes, de Ellis Jr., procurava reafirmar e aprofundar a visão republicana da história paulista, acalentada no interior do IHGSP e, ao mesmo tempo, contestar os fundamentos históricos da crítica às instituições liberais-federalistas elaborada por Oliveira Vianna. A conclusão implícita na obra de Ellis Jr. era a de que, para o caso paulista, não tinha validade a crítica levantada pelo pensador fluminense. $O$ tipo paulista, particularista, herdeiro de um bandeirante mestiço, predominantemente plebeu e "psicologicamente" democrático, fruto de uma São Paulo de secular tradição de self-government, era tão adequado às instituições federalistas e liberais quanto o norte-americano, do qual se aproximava. No caso paulista, a democracia liberal não era algo inadequado à realidade e à tradição. Ao contrário, ela era apresentada por Ellis Jr. como a própria essência da tradição regional. Apresentando o tipo 
paulista como o mais apto ao regime democrático-liberal, Ellis Jr. legitimava não somente os valores liberais federalistas das instituições políticas vigentes, mas também a liderança política da elite paulista em âmbito nacional, procurando soldar as rachaduras de um edifício que, nos anos 1920, ameaçava ruir.

Notas

1. Entre a longa produção sobre o mito bandeirante, podemos destacar Abud (1985), Queiroz (1992), Monteiro (1994), Luca (1999) e Ferreira (2002).

2. Abordagens predominantemente políticas do símbolo bandeirante foram pioneiramente feitas, a partir de questionamentos diferentes, por Maria Helena Capelato (1985: 30-41) e Marly Silva Motta (1992: 79-115).

3. Sobre o liberalismo americanista de Tavares Bastos, ver Viana (1993) e Ferreira (1999).

4. Apropriado por latifundiários escravocratas, ou setores a eles ligados, o americanismo dos republicanos paulistas veio desprovido dos traços mais radicais

\section{Referências bibliográficas}

ABUD, Kátia. 1985. O sangue intimorato e as nobilíssimas tradições: a construção de um símbolo paulista: $o$ Bandeirante. São Paulo, USP (Tese de Doutorado).

ADUCCI, Cassia Chrispiniano. 2000. A pátria paulista. São Paulo: Arquivo do Estado/ Imprensa Oficial. e socialmente transformadores (como o vigoroso abolicionismo e a defesa da reforma agrária) do americanismo da vertente representada por André Rebouças, estudada por Maria Alice Resende de Carvalho (1998). Sobre o caráter autoritário do liberalismo republicano paulista, ver Maria Helena Capelato (1985: 23).

5. A esse respeito, ver minha tese de doutorado: Ferretti (2004: 159-160).

6. Várias foram as análises da interpretação do passado brasileiro em Oliveira Vianna. Entre elas, podemos citar Viana (1993), Carvalho (1993) e Odália (1997).

AZEVEDO MARQUES, Manuel Eufrásio. 1954. Apontamentos históricos, geográficos, biográficos, estatísticos, noticiosos da província de São Paulo. São Paulo: Comissão IV Centenário.

BRASILIENSE, Américo. 1878. O programa dos partidos no Segundo Império. São Paulo: Typ. Jorge Stockler. 
1875. Lições de história pátria.

São Paulo: Typ. da Província.

BRESCIANI, Maria Stella. 1993. O

cidadão da República: liberalismo x positivismo; Brasil: 1870-1900. Revista USP, São Paulo. Dossiê liberalismo/neoliberalismo.

CAPELATO, Maria Helena R. 1985. Os arautos do liberalismo. São Paulo: Brasiliense.

CARVALHO, José Murilo de. 1993. A utopia de Oliveira Vianna. In: BASTOS, Élide Rugai \& MORAES, João Quartim. O pensamento de Oliveira Vianna. Campinas: Ed. Unicamp.

CARVALHO, Maria Alice Resende de. 1998. O quinto século. André Rebouças e a construção do Brasil. Rio de Janeiro: Revan/Iuperj.

CASALECCHI, José Enio. 1987. O Partido Republicano Paulista: política e poder (1889-1926). São Paulo: Brasiliense.

DE CERTEAU, Michel. 2000. $A$ escrita $d a$ história. Rio de Janeiro: Forense Universitária.

DOSSE, François. 2004. Michel de Certeau e a história: entre o dizer e o fazer. In: . História e ciências sociais. Bauru: Edusc.

ELLIS Jr., Alfredo. 1926. Raça de gigantes. São Paulo: Hélios.

FERREIRA, Antônio Celso. 2002. Epopéia bandeirante: letrados, instituições, invenção histórica (1870-1940). São Paulo: Ed. Unesp.

FERREIRA, Gabriela Nunes. 1999. Centralização e descentralização no Império. A polêmica entre Tavares Bastos e o Visconde do Uruguai. São Paulo: Dep. de Ciências Políticas da USP/ Editora 34.
FERRETTI, Danilo J. Zioni. 2004. $A$ Construção da paulistanidade. Identidade, historiografia e política em São Paulo (1856-1930). São Paulo, USP (Tese de Doutorado).

HARTOG, François \& REVEL, Jacques (dir.). 2001. Les usages politiques $d u$ passé. Paris: Ed. Ehess.

LUCA, Tânia Regina de. 1999. A Revista do Brasil: um diagnóstico para a (N)ação. São Paulo: Ed. Unesp.

MAGALHÃES, Basílio de. 1913. O estado de São Paulo e o seu progresso na atualidade. Rio de Janeiro: Jornal do Comércio.

MARTINS, Joaquim Pedro de Oliveira. 1978. O Brasil e as colônias portuguesas. Lisboa: Guimarães \& Cia.

MONTEIRO, John M. 1994.

Caçando com gato: raça, mestiçagem e identidade paulista na obra de Alfredo Ellis Jr. Novos Estudos Cebrap, São Paulo, n. 32.

MOTTA, Marly Silva da. 1992. A nação faz 100 anos: a questão nacional no centenário da independência. Rio de Janeiro: Editora FGV.

ODÁLIA, Nilo. 1997. As formas do mesmo. Ensaio sobre o pensamento historiográfico de Varnhagen e Oliveira Vianna. São Paulo: Unesp.

OLIVEIRA VIANNA, Francisco J. 1920. Populações meridionais do Brasil. São Paulo: Ed. Monteiro Lobato. [1921] 1930. Pequenos estudos de psicologia social. . [1923] 1956. Evolução do povo brasileiro. Rio de Janeiro: José Olympio.

.1924. O valor pragmático do estudo do passado. Revista do Brasil, São Paulo, n. 108. 
. [1930] 1981. Problemas de política objetiva.

POLIAKOV, Léon. 1974. O mito ariano: ensaio sobre as fontes do racismo e do nacionalismo. São Paulo: Perspectiva/ Edusp.

QUATOCCHI-WOISSON, Diana. 1992. Un nacionalisme de déracinés. Argentine, pays malade de sa mémoire. Paris : CNRS.

QUEIROZ, Maria Isaura P. de. 1992. O mito bandeirante: vicissitudes de um imaginário. Revista USP, São Paulo, v. 13.

REGO, Walquíria G. D. Leão. 1993. Tavares Bastos e Oliveira Vianna: contraponto. In: BASTOS, Elide \& MORAES, João Q. de (orgs). $O$ pensamento de Oliveira Vianna. São Paulo: Ed. Unicamp.

SÃO PAULO. 1927. Anais da Assembléia Legislativa de São Paulo.

SALLES, Alberto. 1982. A instrução pública nos Estados Unidos e no
Brasil. Alamanach Litterário de São Paulo para o ano de 1879. Ed. fac-similar. São Paulo: Imprensa Oficial.

SOUSA, Washington Luís Pereira. 1918. A capitania de São Paulo. Governo de D. Rodrigo César de Meneses. São Paulo: Casa Typográfica Garreaou.

TORRES, Vasconcelos. 1956. Oliveira Vianna. Sua vida e sua posição nos estudos brasileiros de sociologia. Rio de Janeiro: Freitas Bastos.

VIANA, Luiz Werneck. 1993. Americanistas e iberistas: a polêmica de Oliveira Vianna com Tavares Bastos. In: BASTOS, Elide \& MORAES, João Q. de (orgs). O pensamento de Oliveira Vianna. São Paulo: Ed. Unicamp.

VENANCIO, Giselle Martins. 2003. Na trama do arquivo: a trajetória de Oliveira Vianna (1883-1951). Rio de Janeiro, Instituto de Filosofia e Ciências Sociais - UFRJ (Tese de Doutorado).

\section{Resumo}

Este texto pretende estudar o uso político do passado bandeirante durante a década de 1920, concentrando-se nas obras do pensador antiliberal Oliveira Vianna e de Alfredo Ellis Jr., do Partido Republicano Paulista. Para tanto, segue as observações de Michel de Certeau sobre as três dimensões da operação historiográfica: seu lugar social de produção, os procedimentos de análise e a representação textual empregada. Demonstra-se a pluralidade de sentidos políticos conferidos ao bandeirante pela historiografia e sua relação com o duplo processo de construção de uma identidade regional para São Paulo e de um imaginário americanista, legitimador do republicanismo paulista.

Palavras-chave: historiografia, bandeirante, identidade regional, republicanismo paulista. 


\begin{abstract}
The article studies the political use, during the 1920', of the "bandeirante" past focusing on the work of Oliveira Vianna, an anti-liberal intellectual, and of Alfredo Ellis Jr., a member of the Republican Party of São Paulo. To do so, it follows Michel de Certeau's remarks on the three dimensions of historiographical procedure: the social place of its production, the method employed and the final text. It shows the different political meanings given to the "bandeirante" by historiography, and its relation to the double process of building a regional identity to São Paulo, as well as an americanist identity which would legitimate the "paulista" republicanism.

Key words: historiography, "bandeirante", regional identity, "paulista" republicanism
\end{abstract}

\title{
Résumé
}

Dans ce texte nous étudions l'usage politique du passé "bandeirante" tel qu'il a été fait aux années 1920, en analysant l'oeuvre du penseur antilibéral Oliveira Vianna et celle de Alfredo Ellis Jr., membre du Parti Républicain de São Paulo. Dans notre analyse, nous adoptons les observations de Michel de Certeau sur les trois dimensions de l'opération historiographique: le lieu social de sa production, ses pratiques scientifiques et son écriture. Nous montrons la pluralité de sens politiques conférés au "bandeirante" par l'historiographie et sa relation avec la double construction d'une identité régionale pour São Paulo et d'un imaginaire américaniste capable de légitimer le républicanisme "paulista".

Mots-clefs: historiographie, "bandeirante", identité régionale, repubicanisme "paulista" 